\title{
Nói thêm về cái tiêu đề ngồ ngộ
}

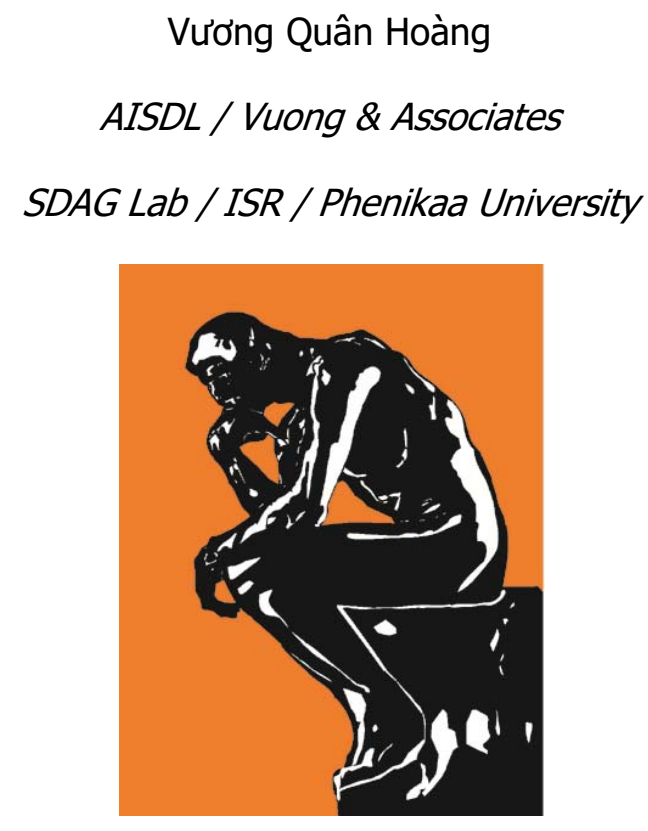

Hà Nội, ngày 20 tháng 7 năm 2021

OSF Preprint, doi: 10.31219/osf.io/dut56

Hôm qua, ngày 19-7, một cuốn sách của SDAG/AISDL được lên kế hoạch biên soạn để phục vụ công việc nghiên cứu và đào tạo từ khá lâu, đã chính thức xuất bản. Bình thường như mọi cuốn sách khác, chỉ có điều tiêu đề cuốn sách thoạt nghe hơi ngồ ngộ: Bản hòa tâu dữ liệu xã hội [1]. Vì nghe nó hơi lạ tai, nên đã vài ba người hỏi lý do. Đoán rằng sẽ còn ai đó nữa có chung câu hỏi, nên tôi viết mây dòng dưới đây để lý giải.

Trước tiên, cần nói sơ về nội dung cuốn sách đề cập. Đây là một tài liệu đáp ứng nhu cầu tự thân của SDAG/AISDL về đào tạo kỹ thuật xử lý dữ liệu trong nghiên cứu khoa học xã hội (KHXH) và hướng tới cải thiện chất lượng các bản thảo nghiên cứu quốc tế. Nhu cầu này không bỗng nhiên mà sinh ra. Nó xuất phát từ việc xuất bản các bài trên các tạp chí uy tín, danh tiếng thường rất khó khăn, nếu các chuẩn mực về phương pháp luận và quy chuẩn xử lý không đạt tới. Chưa hết, thế giới đang trong thời kỳ thích ứng với thống kê Bayesian, nhằm hạn chế bớt những nhược điểm của suy diễn thống kê lệ thuộc vào $p$-value, và sự đòi hỏi ngày càng không có giới hạn về kích thước mẫu thống kê phân tích (điều này trong KHXH khó lòng mà đáp ứng được, vì yếu tố kinh tế, vì điều kiện thực tiễn và vì cả bản chất của bài toán nghiên cứu). ${ }^{1}$

\footnotetext{
${ }^{1}$ Đối với SDAG/AISDL thì yễu tố kinh tế rất quan trọng, do định hướng hiệu quả trên một đơn vị đầu tư nghiên cứu, theo quan điểm [2].
} 
Chúng tôi quan niệm rằng, những thay đổi lớn cần sự thích ứng và chuyển biến suy nghĩ, cuối cùng là thực hành trên công cụ lao động [3]. Do đó, tiếp cận thống kê Bayesian, sử dụng kỹ thuật MCMC, và chương trình máy tính xử lý cho dữ liệu KHXH chạy trên môi trường ngôn ngữ $\mathrm{R}$ là lựa chọn được đánh giá là hợp lý. Rất may mắn, là trong quá trình tiến hành các nghiên cứu, có những lúc đã chọn "việc khó" mà làm; ví dụ như khi đang xử lý bài nghiên cứu [4-5], nhiều khi phải chấp nhận gián đoạn công việc, để phát triển chương trình máy tính. Vì thế, khi các nghiên cứu này xuất bản, thì cũng là lúc chương trình bayesv/ra đời, thông tin được cung cấp chi tiết trong [6-7].

Nói như ở trên là xuôi dòng câu chuyện. Nhưng ngược lại thì không đơn giản. Những vấn đề nêu ở trên có thể quen thuộc với một số nhóm, nhưng có thể không gần gũi với nhiều nhóm nghiên cứu. Hiểu tiếp cận Bayesian với xử lý dữ liệu thống kê yêu cầu khá nhiêu biện luận logic, trước, trong và sau khi tiến hành mô phỏng dữ liệu. Về nguyên lý, công việc biện luận ấy xuất phát ngay từ khi bắt đầu suy nghĩ về các khía cạnh triết học của dữ liệu: bản thể, nhận thức, và tất nhiên, phương pháp. Vì vậy, một yêu cầu cơ bản là qua chương trình bayesvl, phải cố gắng làm sao giúp thúc đẩy khả năng diễn giải, tính sư phạm cho ứng dụng phân tích.

Thế nhưng, nếu lôi tất cả những vấn đề này ra để bây biện cùng với loại ngôn ngữ khô khan thường thấy trong các tài liệu thống kê, thì có thể thu hút các bạn trẻ đang tìm tòi được không? Khả năng là không, vì nghe những thứ này khá là... chán!

Do đó, chúng tôi buộc phải tìm cách gì đó vẫn nói được chuyện cần nói, nhưng nghe sao không khô khan, xơ cứng quá. Và đây là việc không dễ.

May sau, tôi nhớ lại được dăm năm trước có nhìn thấy một bức hình đàn chim đậu trên dây điện, mà lùi ra xa ngắm thì không khác gì một bản nhạc. Thế nên đi lục tìm lại. Viva Internet, tìm là ra ngay.

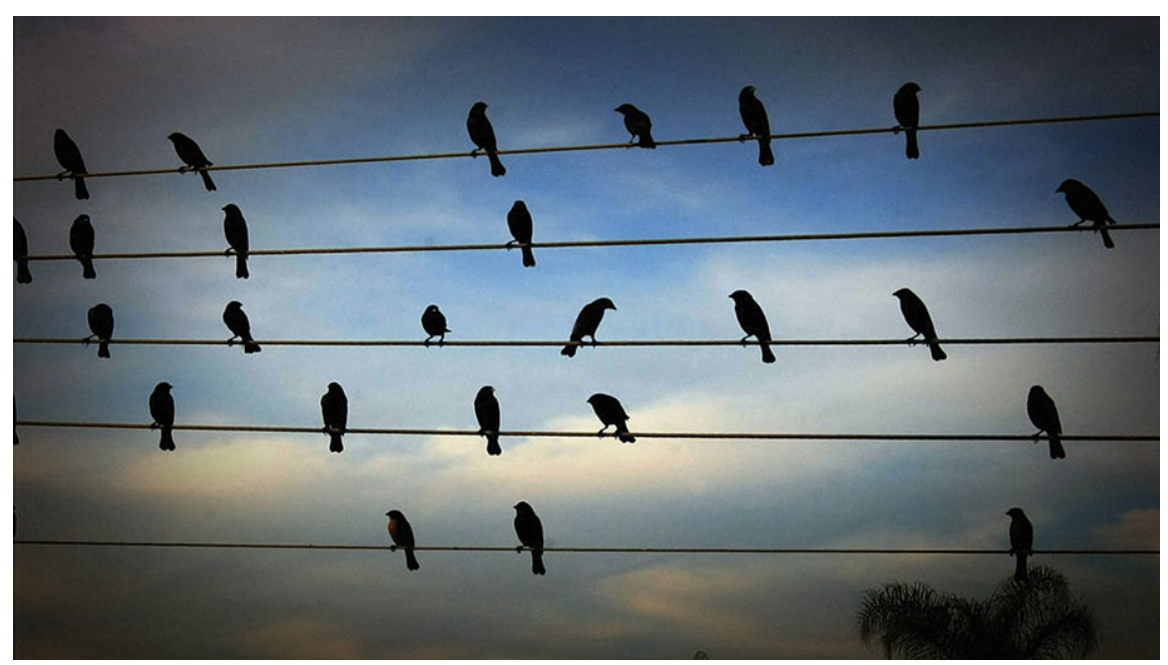

Lẽ tự nhiên, cũng dễ thấy luôn rằng nhiều người khác đã có liên tưởng tới bản nhạc. Thậm chí, một số người còn sản xuất ra những hình ảnh kiểu tương tự như dưới đây. 


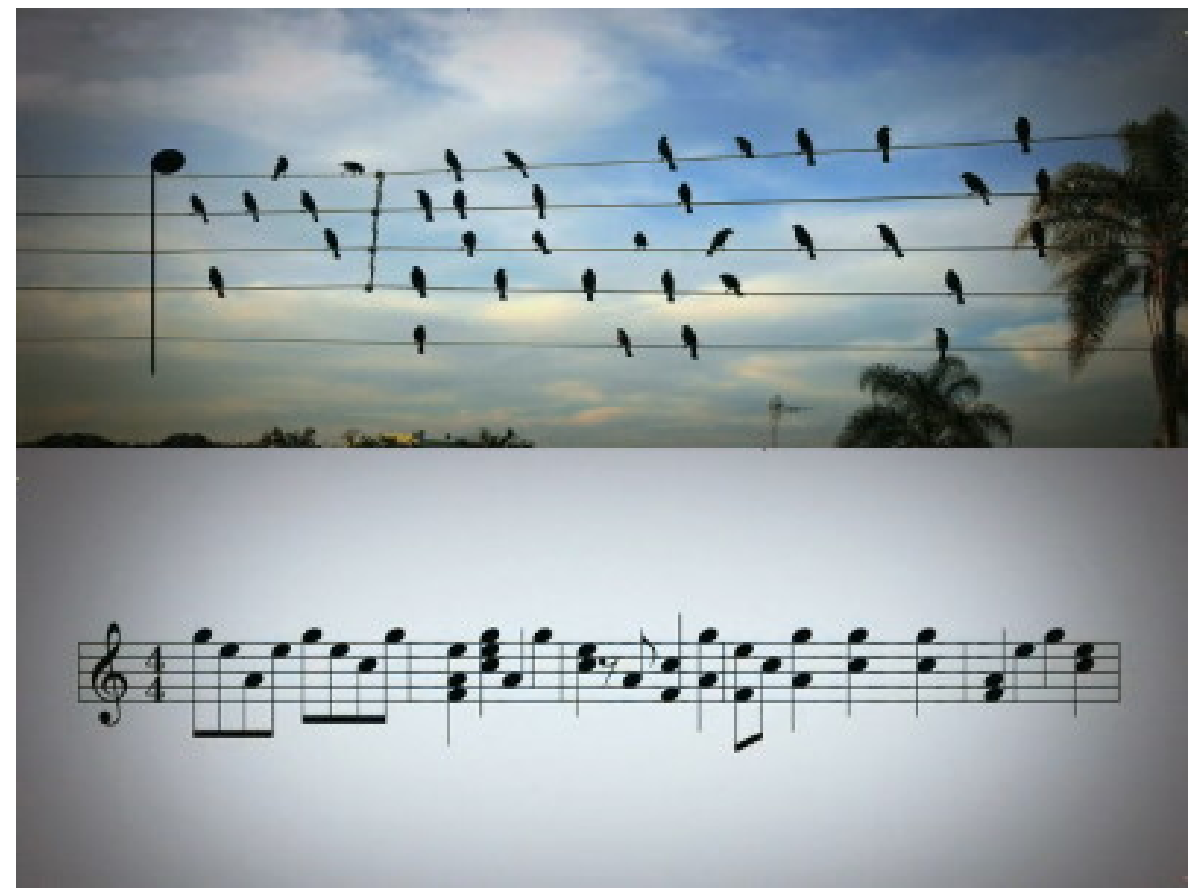

Bản thân tôi cũng hay nghe Chopin, Beethoven, Mendelssohn... những lúc rảnh rỗi, nên có thể nói rằng hình ảnh này đã quyết định việc đặt tiêu đề cho cuốn sách. Đồng thời, ngay trong cuốn sách [1], hình ảnh từa tựa thế này thỉnh thoảng lại xuất hiện, một ví dụ là trang 186, hình 10.9 , minh họa cho kết quả trả về của hàm vẽ bvi_plotIntervals.

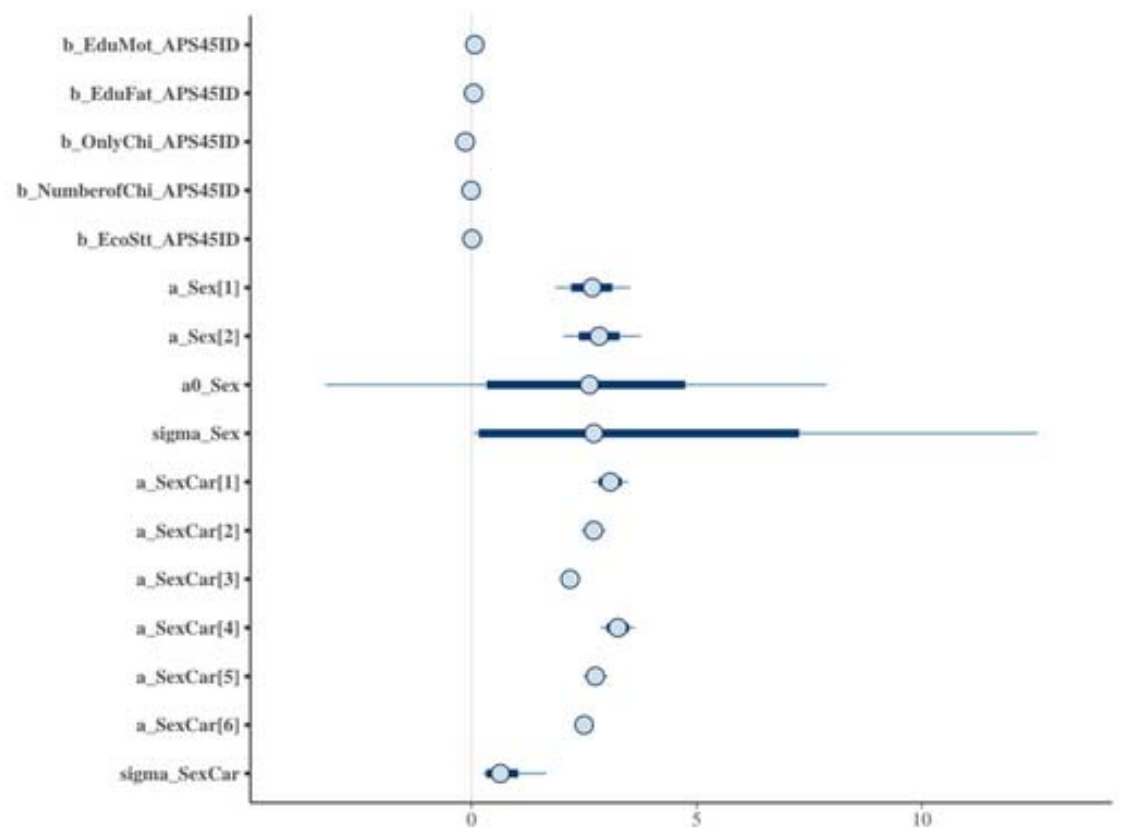

Hình 10.9: Hình Intervals vẽ bởi bayesvl Nguồn: C2021 AISDL và SDAG 
Và rõ ràng, cái tiêu đề này thân thiện hơn, mà cũng không làm mất đi chủ đích của công việc thúc đẩy tiếp cận dữ liệu khoa học xã hội và nhân văn.

Nhưng nói gì thì vẫn phải chờ thời gian và người sử dụng kết luận khách quan. Mọi cuốn sách trên đời này đều có chung raison d'être căn bản: người đọc.

\section{Tài liệu tham khảo:}

[1] Hoàng VQ, Phương LV, Trung T, Hoàng NM, Toàn HM. (2021). Bản hòa tấu dũ liệu xã hội. Nxb Khoa học Xã hội, Hà Nội. ISBN: 978-604-308-549-5. Available at: https://books.google.com/books/?id=eBU5EAAAQBA]

[2] Vuong QH. (2018). The (ir) rational consideration of the cost of science in transition economies. Nature Human Behaviour, 2(1), 5.

[3] Vuong QH. (2019). Breaking barriers in publishing demands a proactive attitude. Nature Human Behaviour, 3(10), 1034.

[4] Vuong QH, et al. (2019). Cultural evolution in Vietnam's early 20th century: A Bayesian networks analysis of Hanoi Franco-Chinese house designs. Social Sciences \& Humanities Open, 1(1), 100001.

[5] Vuong QH, et al. (2020). On how religions could accidentally incite lies and violence: Folktales as a cultural transmitter. Palgrave Communications, 6, 82.

[6] Vuong QH, La VP, Nguyen MH, Ho MT, Ho MT, Mantello P. (2020). Improving Bayesian statistics understanding in the age of Big Data with the bayesvl $\mathrm{R}$ package. Software Impacts, 4, 100016.

[7] Vuong QH, La VP, Nguyen MH, Ho MT, Tran T, Ho MT. (2020). Bayesian analysis for social data: A step-by-step protocol and interpretation. MethodsX, 7, 100924. 